\title{
Music-based interventions in palliative cancer care: a review of quantitative studies and neurobiological literature
}

\author{
Patrick Archie • Eduardo Bruera • Lorenzo Cohen
}

Received: 19 April 2012 /Accepted: 21 April 2013 /Published online: 30 May 2013

(C) The Author(s) 2013. This article is published with open access at Springerlink.com

\begin{abstract}
Purpose This study aimed to review quantitative literature pertaining to studies of music-based interventions in palliative cancer care and to review the neurobiological literature that may bare relevance to the findings from these studies. Methods A narrative review was performed, with particular emphasis on RCTs, meta-analyses, and systematic reviews. The Cochrane Library, Ovid, PubMed, CINAHL Plus, PsycINFO, and ProQuest were searched for the subject headings music, music therapy, cancer, oncology, palliative care, pain, anxiety, depression, mood, quality of life, prevalence, neuroscience, functional imaging, endogenous opioids, GABA, 5HT, dopamine, and permutations of these same search terms. Data for the review were comprised of articles published between 1970 and 2012. References of all the cited articles were also reviewed.

Results Available evidence suggests that music-based interventions may have a positive impact on pain, anxiety, mood disturbance, and quality of life in cancer patients. Advances in neurobiology may provide insight into the potential mechanisms by which music impacts these outcomes.

Conclusions More research is needed to determine what subpopulation of cancer patients is most likely to respond to music-based interventions, what interventions are most
\end{abstract}

P. Archie $(\bowtie)$

Celilo Cancer Center, Mid-Columbia Medical Center,

1800 East 19th Street, The Dalles, OR 97058, USA

e-mail: patrick.the.oncologist@gmail.com

E. Bruera

Department of Palliative Care and Rehabilitation Medicine, Division of Cancer Medicine, The University of Texas MD

Anderson Cancer Center, Houston, TX, USA

\section{Cohen}

Integrative Medicine Program, Department of General Oncology, Division of Cancer Medicine, The University of Texas MD

Anderson Cancer Center, Houston, TX, USA effective for individual outcomes, and what measurement parameters best gauge their effectiveness.

Keywords Music $\cdot$ Cancer $\cdot$ Oncology $\cdot$ Palliative $\cdot$ Neurobiology

\section{Introduction}

By alleviating the physical and psychological symptoms associated with malignancy, palliative care serves a vital role in the multidisciplinary care of cancer patients. Common symptoms such as pain, anxiety, and mood disturbance can be difficult to manage with standard pharmaceutical options and may significantly interfere with quality of life (QOL) [1, 2]. The search for complimentary interventions that are both cost effective and associated with few side effects has led to an increased interest in the therapeutic use of music for cancer patients within the field of palliative care [3-6]. This review summarizes findings from quantitative research literature. Furthermore, it discusses challenges and opportunities associated with this emerging area of research and provides practical suggestions for future investigation.

\section{Different music-based interventions defined}

The interventions in this review are generally classified as either music medicine or music therapy. In "music medicine" interventions, patients listen to prerecorded music that is administered by healthcare staff and preselected by study investigators, who may or may not have any formal training in music therapy $[7,8]$. In "music therapy" interventions, patients are offered prerecorded, live, and/or interactive music that is individualized by a trained music therapist $[9,10]$. Hence, the crucial distinction between music medicine 
(MM) and music therapy (MT) is that the former involves only a stimulus and response, and the latter involves a therapeutic relationship based on individualized assessment, treatment, and evaluation [7].

\section{Specific clinical endpoints studied}

\section{Pain}

Pain represents one of the most common symptoms affecting patients with advanced malignancy. One recent metaanalysis [11] pooled data from 52 studies (total $N=19,985$ ) and estimated pain to occur in $33 \%$ of patients who had completed treatment with curative intent, $59 \%$ of patients undergoing anticancer therapy, and $64 \%$ of patients with advanced/metastatic/terminal disease. A subsequent meta-analysis [12] pooled data from 64 studies (total $N=95,159), 34$ of which reported pain prevalence in patients with all stages of cancer (including early disease), and 30 of which reported pain prevalence in patients with advanced cancer. The combined weighted mean prevalence of pain in the 14,961 patients with advanced cancer was estimated to be $75 \%$.

Multiple studies have demonstrated that music-based interventions may have a mild to moderate analgesic effect (Table 1). Five such randomized controlled trials (RCTs) (total $N=391$ ) were analyzed in a 2011 Cochrane Review [13]. Prerecorded music was provided perioperatively for 15 out of 30 breast cancer patients undergoing mastectomy [14], during bone marrow biopsy for 29 out of 59 hematologic malignancy patients [15], as a single 30-min session in 62 out of 126 adult patients with various malignancies [16], during lumbar puncture in 20 out of 40 pediatric leukemia patients [17], and as a single session with guided imagery in 65 out of 136 adult patients with various malignancies [18]. Based on the combined results of these five studies, the authors classified music's analgesic effect as moderate, with a standardized mean difference (SMD) of $-0.59,(95 \% \mathrm{CI}$ from -0.92 to $-0.27, P=0.0003)$. All five of the above studies reported pain by self-reported measurement scales. An earlier Cochrane Review examined the effect of music on analgesic requirements during a painful procedure (five studies), during a 2-h postoperative period (three studies), or during a 24-h postoperative period (five studies) [19]. Although none of the included studies were limited to oncologic or palliative care settings, the 13 included studies $(N=$ 1016) did show that exposure to music was associated with a decrease in opioid requirement, with a SMD of -1.29 (95\% CI from -0.92 to $-0.27, P=0.0062$ ). These results were consistent with those from a separate meta-analysis [20] which studied the use of music vs. standard care in adult patients undergoing colonoscopy. This meta-analysis included three trials [21-23] in which music was provided to a total of 130 out of 261 patients. The patients who received music required $29.7 \%$ less analgesia with meperidine, alfentanil, or pethidine $(P=0.001)$ and $15 \%$ less sedation with midazolam or propofol $(P=0.055)$. Finally, a single-arm study from 2006 [5] found that in 126 palliative care patients with pain ( $90 \%$ of whom had cancer), mean self-reported pain scores decreased from 2.7 to 2.1 on a fivepoint VAS after a single MT session $(P<0.001)$.

Overall, these data (derived exclusively from MM-based approaches except for [5]) support the use of music to decrease subjective pain and analgesic requirements in acute pain settings. However, more research is needed to investigate the analgesic efficacy of music for chronic pain, since cancer patients (particularly those in palliative care settings) frequently suffer from chronic pain (e.g., from bone metastases, visceral tumor growth, neuropathic pain associated with chemotherapy, etc.). In future studies investigating music-based interventions for chronic pain, careful consideration should be given to the frequency, duration, and type of interventions used (e.g., consideration of interventions not necessarily limited to MM).

\section{Anxiety}

For many patients, the diagnosis of cancer can result in significant anxiety, which can interfere with sleep [24], enjoyment of life [25], interpersonal relationships [26], and overall daily activities [27]. Six studies using survey instruments found self-reported anxiety symptoms to be present in $19-48 \%$ of cancer patients $[1,24,28-31]$. In contrast, three studies using structured clinical interviews found DSM-IVdefined Anxiety Disorders (e.g., generalized anxiety disorder, panic disorder, and post-traumatic stress disorder) to be present in 7.6 to $18 \%$ of cancer patients [24, 32, 33].

Several studies have demonstrated that music-based interventions may have a mild to moderate anxiolytic effect (Table 2). Seven such studies (six RCTs and one controlled clinical trial (CCT), total $N=386$ ) using self-report outcomes were analyzed in the 2011 Cochrane Review [13]. Music was provided perioperatively for 15 out of 30 breast cancer patients undergoing mastectomy [14], during invasive procedures for 20 out of 39 pediatric cancer patients [34], directly prior to the administration of adjuvant chemotherapy for 30 out of 60 breast cancer patients [35], during bone marrow biopsy for 29 out of 59 adults with hematologic malignancy [15], during chemotherapy for 10 out of 20 adult cancer patients [36], during radiation therapy for 19 out of 42 adult cancer patients [37], and as a single 30-min session for 65 out of 136 adult cancer patients with pain [18]. Based on the combined results of these seven studies, the SMD on the 80-point State-Trait Anxiety Inventory Scale (STAI-S) was -11.20 units $(95 \%$ CI -19.59 to $-2.82, P=0.0088)$. These results were consistent 


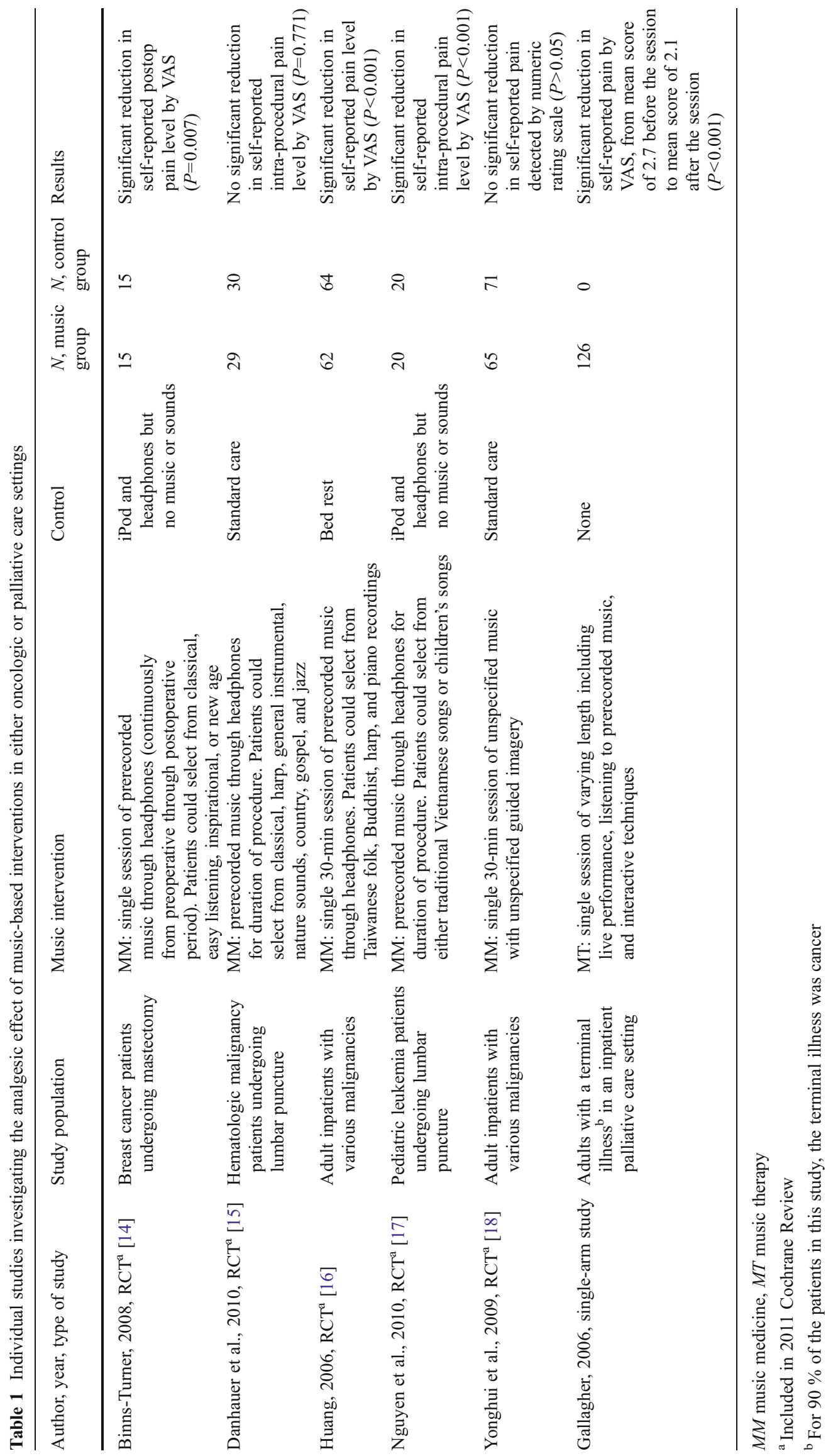




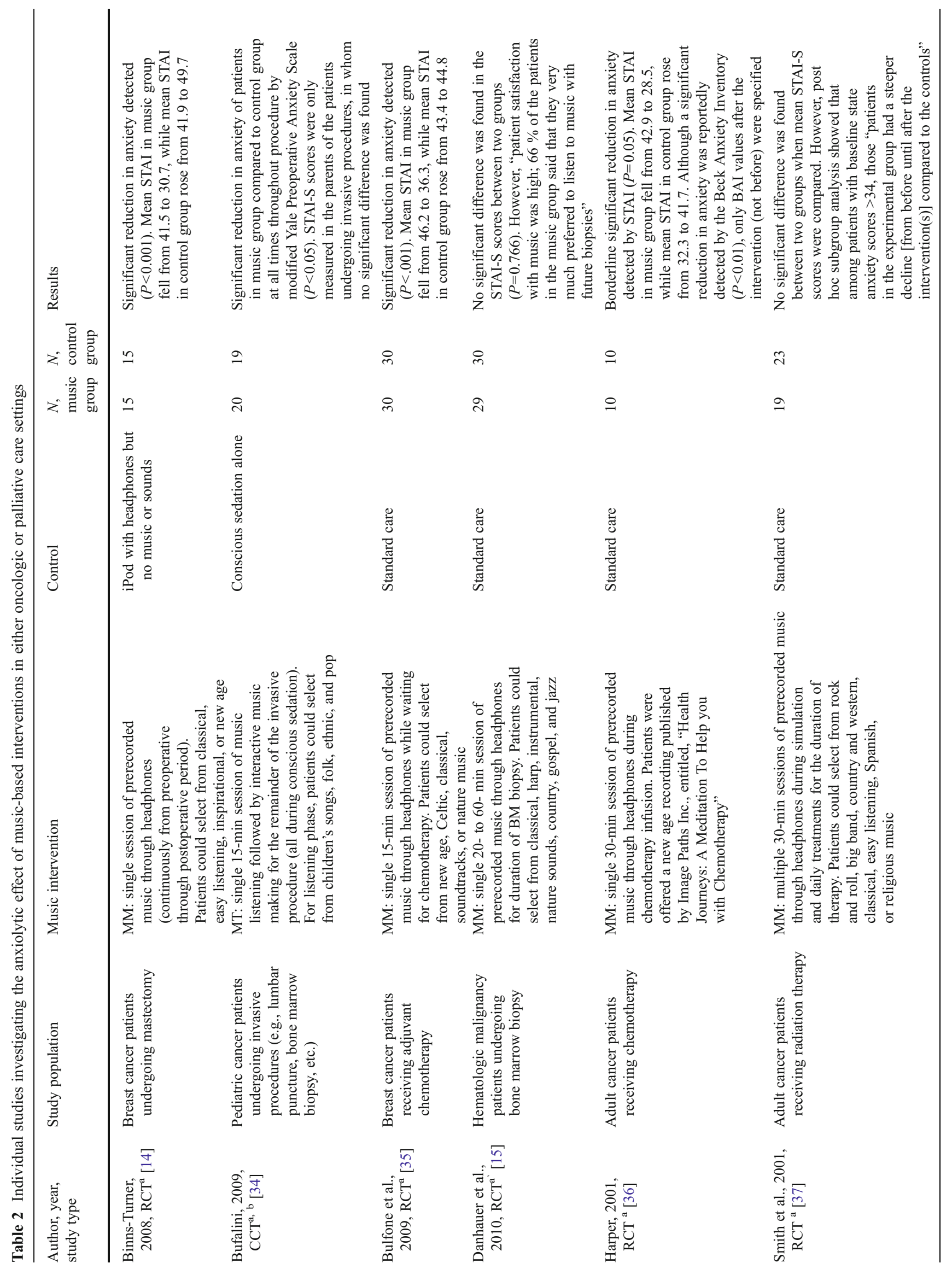




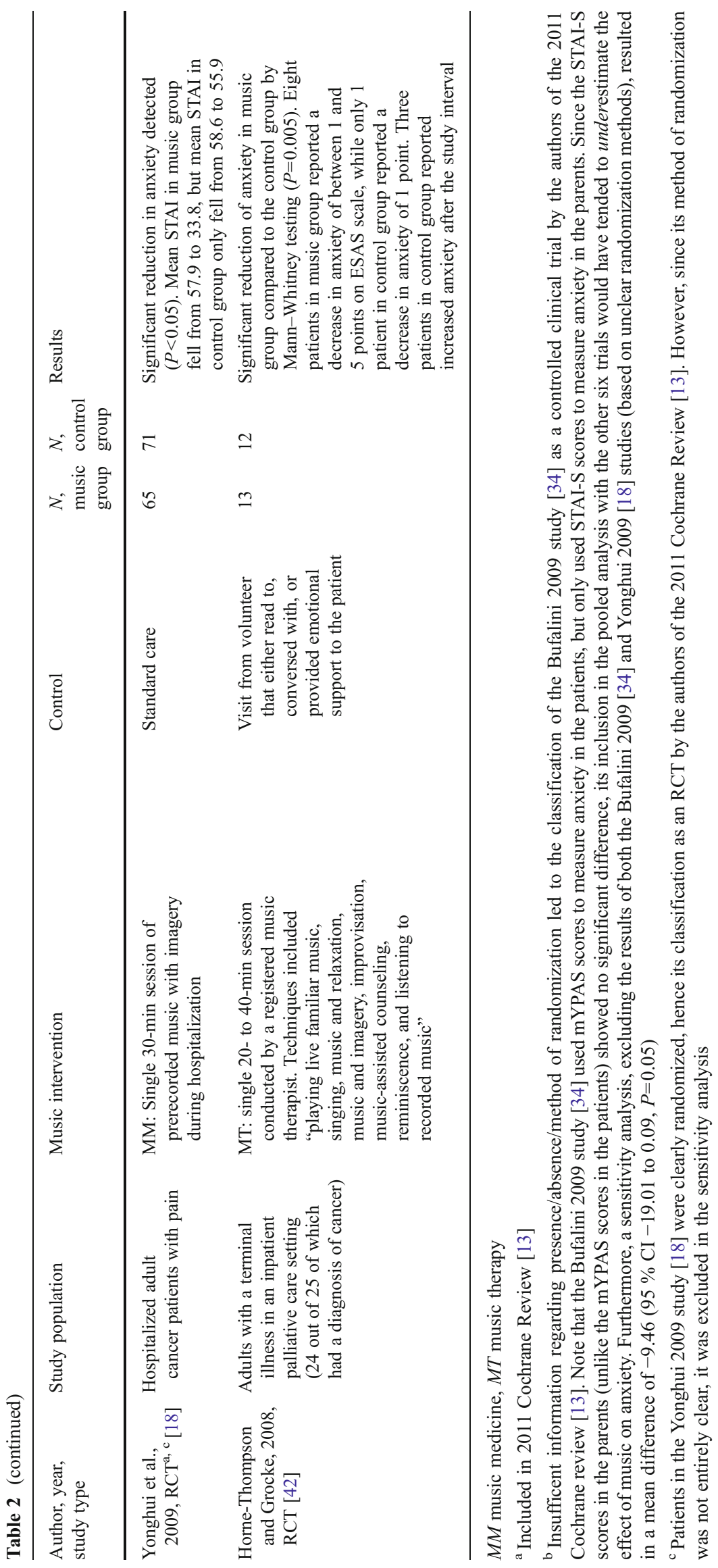


with those from four other RCTs involving patients without cancer, in whom perioperative anxiety was significantly reduced by music-based interventions [38-41]. One small but well-designed RCT specifically examined the effectiveness of a single 20-40-min MT session in reducing anxiety for terminally ill patients [42]. Although cancer was not an inclusion criterion, 24 out of 25 patients in the study had cancer, and all study participants were inpatients receiving palliative care services. Based on the Edmonton Symptom Assessment Scale anxiety scores before and after the intervention, the MannWhitney test showed that anxiety was significantly reduced in the music group compared to the control group $(P=0.005)$.

Overall, these data (derived from six studies using MM and two studies using MT) support the use of music to reduce anxiety in situations such as before/during invasive procedures, chemotherapy, and radiation therapy. Relatively less is known about music's capacity to decrease the need for pharmacologic anxiolytics/sedatives/hypnotics. Although one stud$y$ in 327 patients undergoing elective surgery showed a greater decrease in preoperative STAI-S scores with relaxing music than $0.05-0.1 \mathrm{mg} / \mathrm{kg}$ of midazolam $(P<0.001)$ [43], the relevance of this finding to the oncologic and palliative care settings remains uncertain. Furthermore, more research is needed to investigate the anxiolytic efficacy of music beyond the acute/situational anxiety setting, particularly for cancer patients in whom the recognition of disease progression and impending death may be particularly anxiety inducing $[44,45]$.

\section{Mood disturbance}

The period following diagnosis of cancer can be very emotional for many patients. Patients with frequent depressive symptoms may develop a sustained disturbance of mood and may eventually meet criteria for a DSM-IV-defined Affective Disorder (e.g., major depressive disorder or dysthymic disorder). Prevalence studies suggest that self-reported depressive symptoms in patients with cancer are common and perhaps more common in the terminal/advanced setting [46-49]. Four studies using survey instruments found depressive symptoms present in 53-74\% of cancer patients [46, 50-52]. A much more recent meta-analysis of 94 interview-based studies estimated the combined mean prevalence of major depressive disorder and dysthymic disorder in palliative and hematologic-oncologic settings [53]. From the 24 studies conducted in palliative care settings (total $N=4,007$ ), the combined mean prevalence of these two disorders was found to be $24.6 \%$. From the 70 studies conducted in hematology-oncology settings (total $N=10,071$ ), combined mean prevalence was found to be $20.7 \%$. To place these numbers in context, the NIMH estimates the combined prevalence of major depressive disorder and dysthymic disorder to be $8.2 \%$ among US adults (two to three times lower than in cancer patients).
While multiple studies have found that music-based interventions may have a positive impact on mood (Table 3 ), this has not necessarily been the case for depression. Such a discrepancy may be at least partially explained by differences between methods used to assess mood disturbance versus those used to assess depression. For example, the commonly used Profile of Mood States (POMS) uses six domains to calculate a total mood disturbance score: depression-dejection, tension-anxiety, anger-hostility, fatigue-inertia, confusion-bewilderment, and vigor-activity. The first five domains are weighted positively and the last domain is weighted negatively, such that a higher score indicates a greater disturbance of mood. Henceforth, music could elicit improvement in mood via the five other domains but not in "depression/dejection." This difference in outcomes was well illustrated in a 2011 Cochrane Review [13], which analyzed five trials examining the effect of music on depression (total $N=468$ patients). Music was provided for 128 out of 182 adults with cancer receiving chemotherapy or radiation therapy [54], 34 out of 60 adults with hematologic malignancy admitted for autologous SCT [55], 27 out of 48 adults with cancer undergoing radiation therapy [56], 20 out of 42 women with metastatic breast cancer [57], and 65 out of 136 adult cancer patients with pain [18]. The pooled estimate from these five trials did not find a statistically significant effect of music on depression $(\mathrm{SMD}=-0.07$, $95 \% \mathrm{CI}-0.40$ to $0.27, P=0.69$ ). However, the same metaanalysis analyzed three trials examining the effect of music on mood (total $N=105$ ), and the pooled estimate from these three studies did demonstrate a statistically significant effect ( $\mathrm{SMD}=0.42,95 \%$ CI 0.03 to $0.81, P=0.03$ ). These three studies investigating the outcome of mood provided music to 8 out of 15 adults with cancer-related pain [58], 34 out of 60 adults with hematologic malignancy admitted for autologous SCT [55], and 15 out of 30 children with neoplasms needing chemotherapy [59]. That Cassileth's same study [55] showed no effect on depression, but did show an effect on mood, supports the idea that the difference between these two outcomes may be more than semantic. Among the 123 palliative care patients with mood disturbance in the singlearm study of Gallagher et al. in 2006 [5], mean self-reported mood disturbance scores improved from 1.8 to 0.7 on a fivepoint VAS after a single MT session $(P<0.001)$.

Overall, the limited data available regarding the outcome of mood (derived from three studies using MT and one study using MM) suggest that music may have a mild positive impact on the mood of cancer patients. Considering that the effects of music-based interventions on pain and anxiety have been most well demonstrated in acute settings, it may not be surprising that a single intervention (MM or MT based) may not show as much impact on mood disturbance, particularly chronically depressed mood. The availability of fast-acting pharmacologic analgesics and anxiolytics, versus 


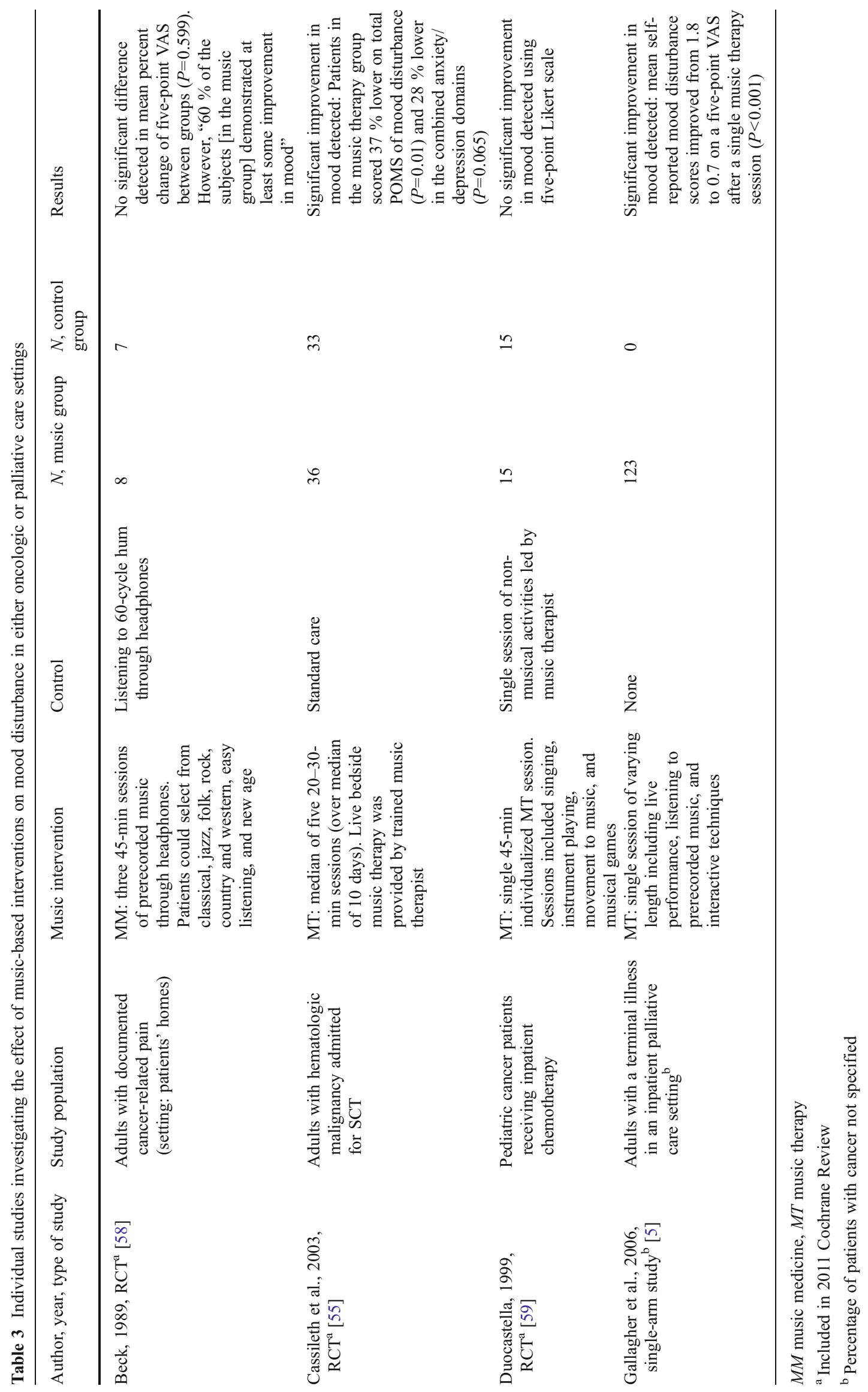




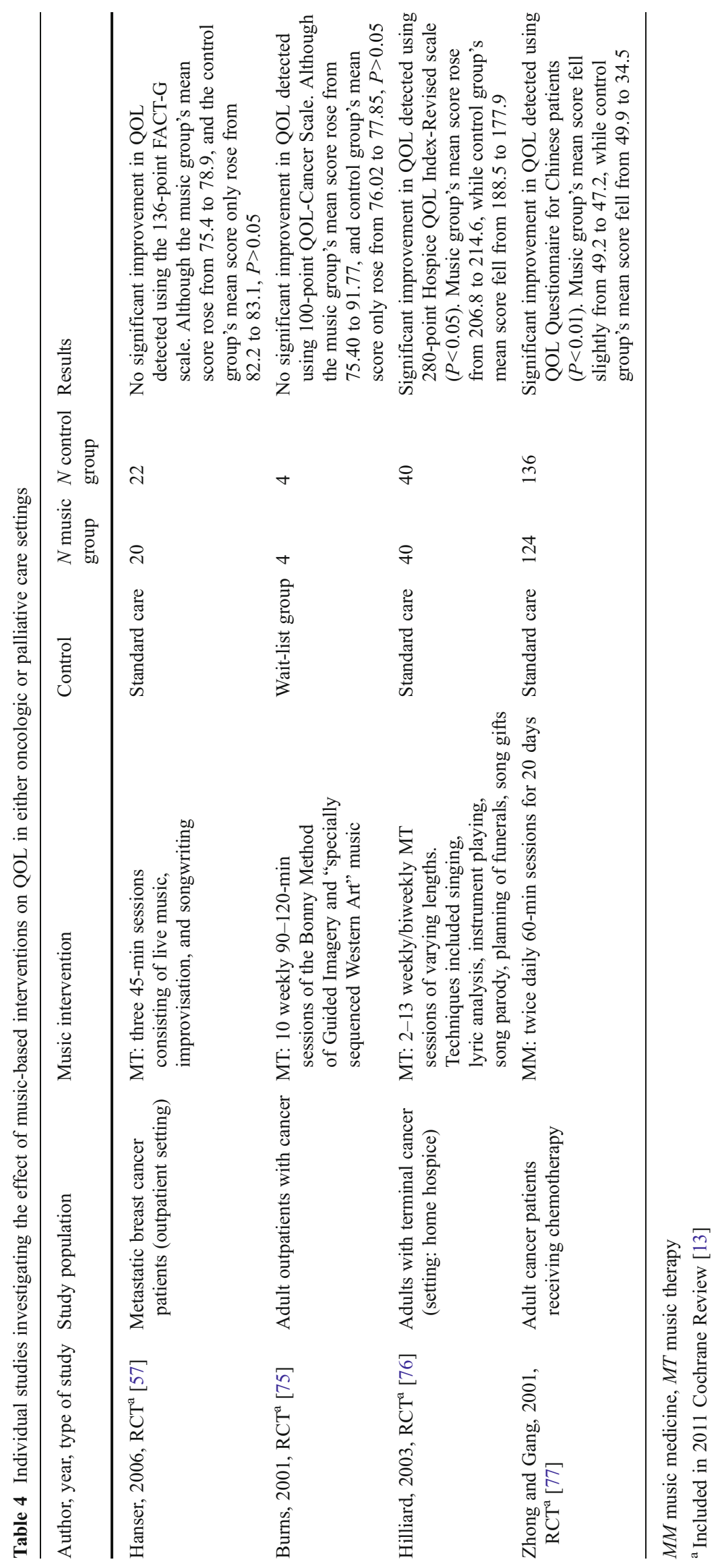




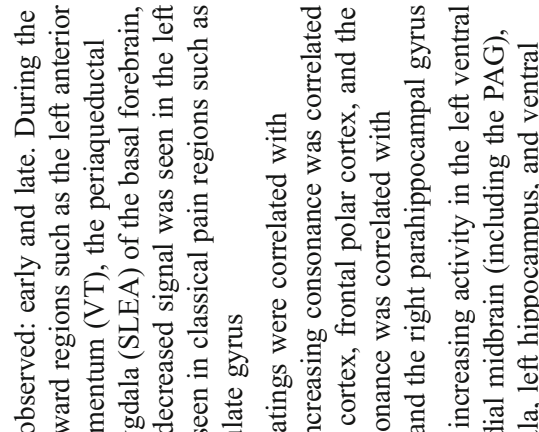

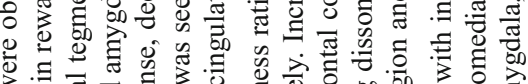

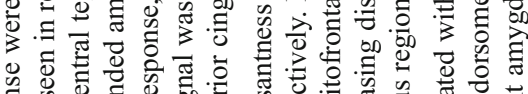

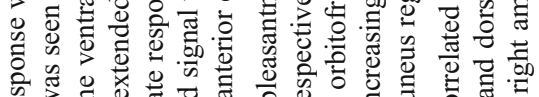

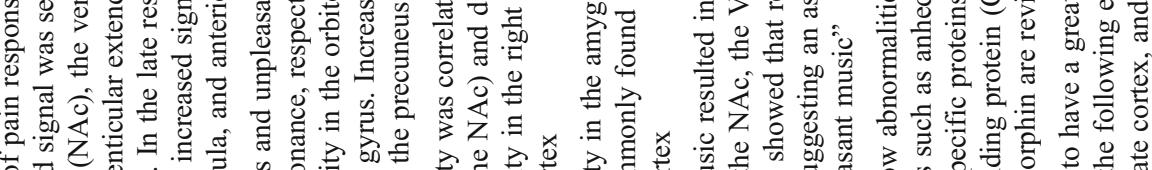

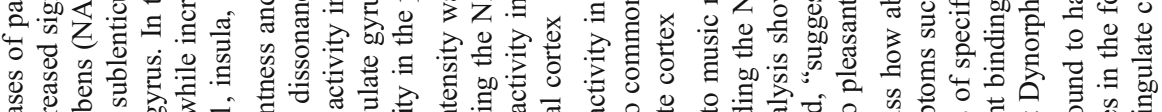

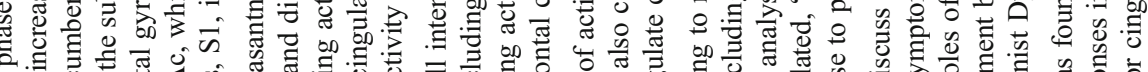

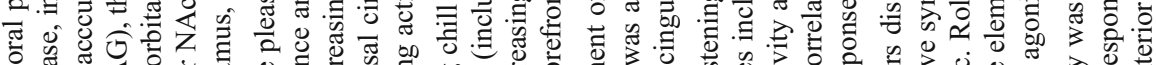

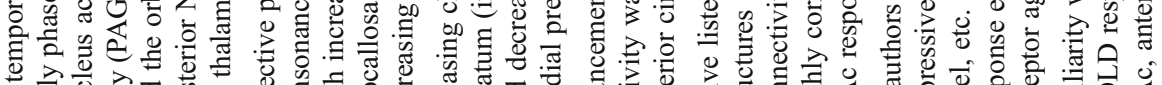

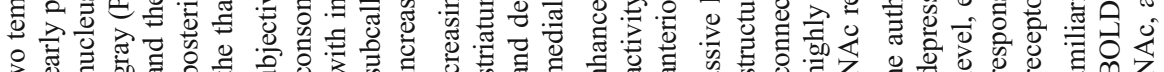

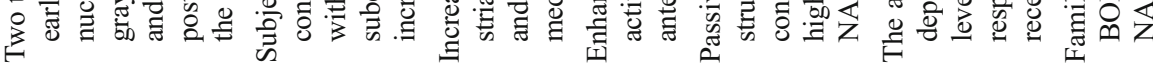

\begin{tabular}{|c|c|}
\hline \multirow[t]{2}{*}{ 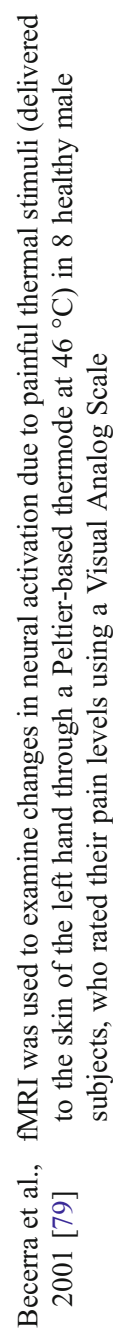 } & 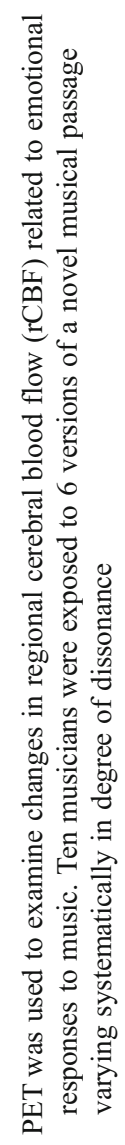 \\
\hline & 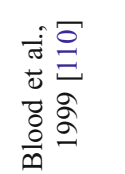 \\
\hline
\end{tabular}

\section{ㅇำ}

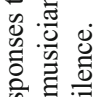

:

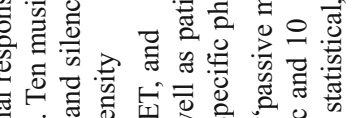

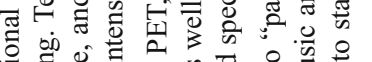

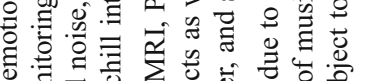

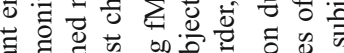

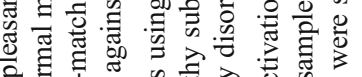

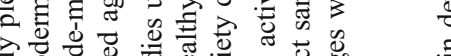

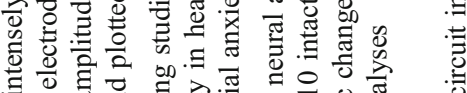

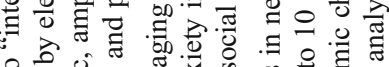

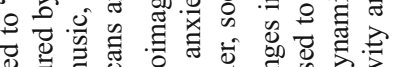

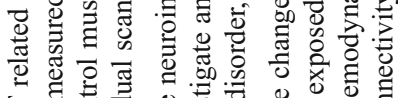

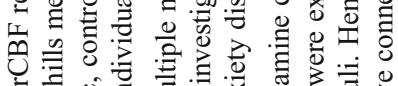

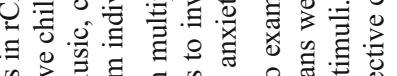

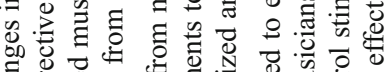

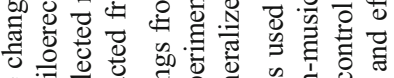

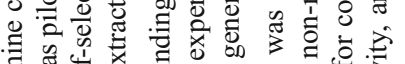

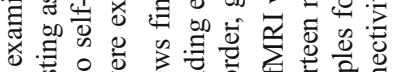

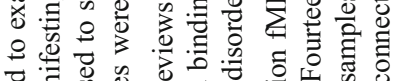

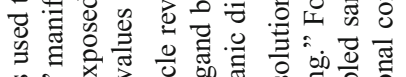

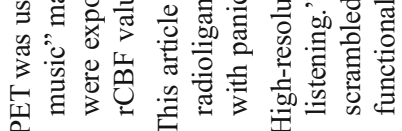

물

范

응

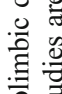

寻

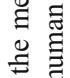

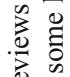

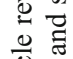

旁:

量到

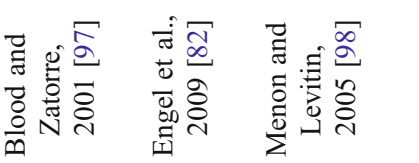

.

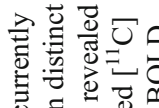

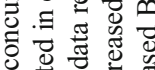

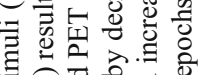

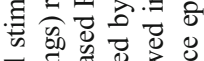

可

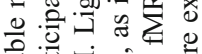

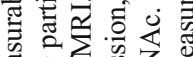

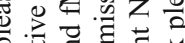

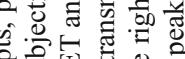

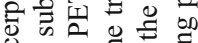

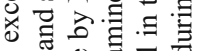

. 语

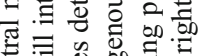

氜包

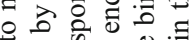

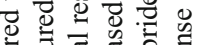

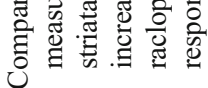

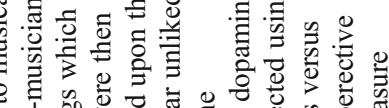

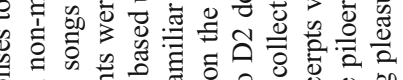

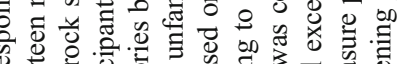

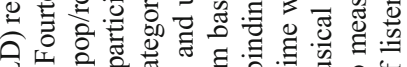

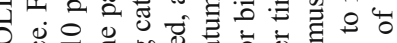

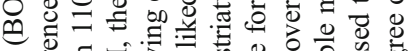

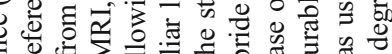

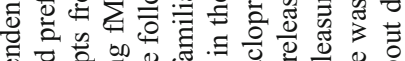

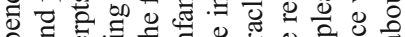

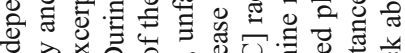

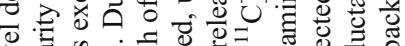

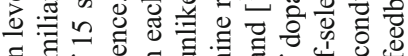

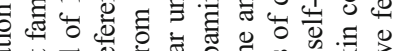

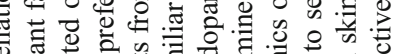

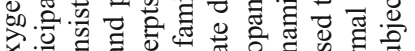

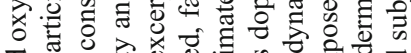

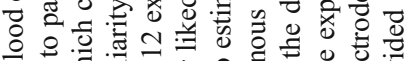
응

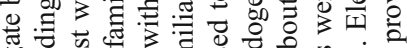

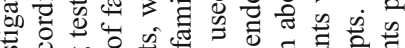
क

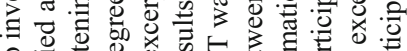
을.

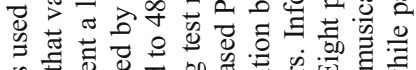

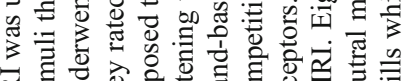

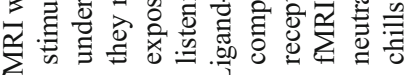
高

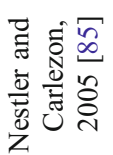

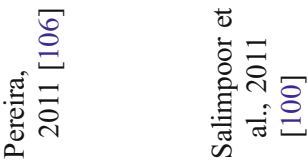


the unavailability of any fast-acting pharmacologic antidepressant, may point toward potentially important neurobiological differences underlying these symptoms. With this in mind, particular consideration should be given to the frequency and duration (as well as the type) of interventions in future studies investigating the impact of music on mood in cancer patients.

\section{Quality of life}

Although there may be less prevalence data measuring overall QOL impairment in cancer patients (relative to pain, anxiety, and depression), the available data suggest that cancer is indeed associated with impaired QOL compared to the normal population [60-62]. This association could be expected for a number of reasons: first, because pain, anxiety, and depression are frequently incorporated into the tools used to measure HR-QOL in cancer patients; secondly, because all three of these symptoms have been shown to commonly affect patients with cancer [63]; and finally, because multiple studies in patients with multiple types of cancer have demonstrated independent associations between HR-QOL impairment and pain [64-68], anxiety [69-71], and depression [72-74].

Although the impact of music-based interventions on QOL has not been as extensively studied as pain, anxiety, or mood disturbance, four RCTs analyzed in the 2011 Cochrane Review [13] compared the impact of musicbased interventions to standard care on QOL scores (Table 4). Clearly, QOL represents a more complex and multi-faceted outcome than pain, anxiety, or depression, and the comparison of results from these four studies was made even more complex by the fact that they all used different QOL assessment tools. In one of the four studies [57], pretest differences were too large for the results to be included in the pooled estimate. Through the other three trials, music was offered to 4 of 8 adults with cancer [75], 40 out of 80 adults with terminal cancer [76], and 124 out of 260 cancer patients receiving chemotherapy [77]. When the results from these three trials were subject to meta-analysis, a heterogeneous, nonsignificant effect was found ( $\mathrm{SMD}=2.01$, $95 \% \mathrm{CI}-0.09$ to $4.11, P=0.06)$. Paradoxically, this nonsignificance actually resulted from a much larger beneficial effect reported in the study by Zhong [77] than that reported in the studies by Burns [75] and Hilliard [76]. When the results from the Burns and Hilliard studies were subject to meta-analysis $(N=88)$, this resulted in a homogenous and significant effect of MT on QOL (SMD $=1.02,95 \% \mathrm{CI} 0.58$ to $1.47, P=0.00001)$. One interesting aspect of the Hilliard study was that even as the physical health of the patients in the music group declined, QOL scores improved. This was not the case in the control group, in whom QOL scores worsened as their physical health declined [76].
Clearly, more research is needed to investigate the impact of music on QOL. Given the crucial importance of this

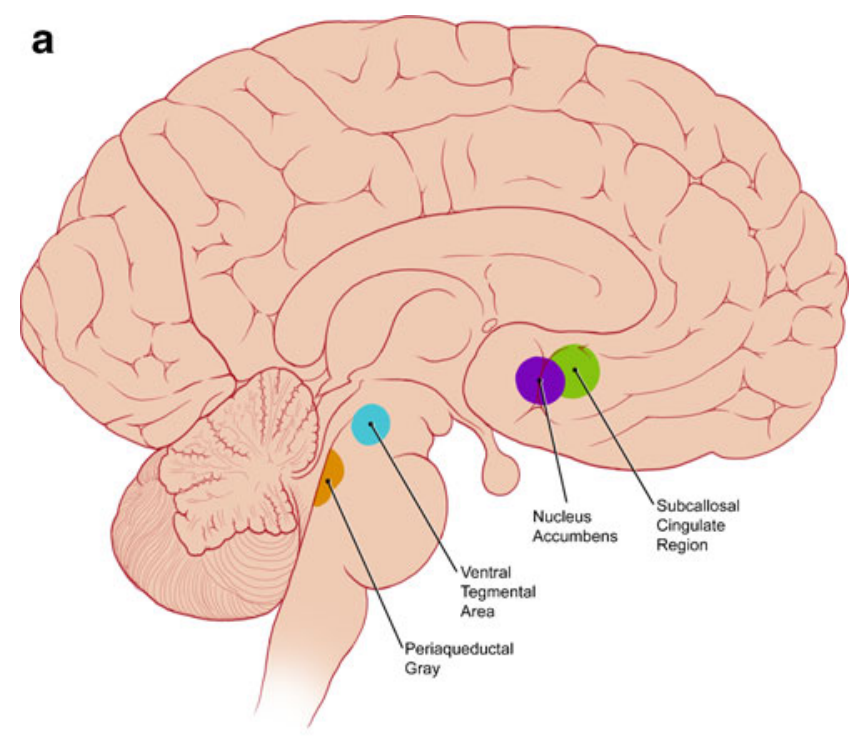

b

\section{Amygdala}

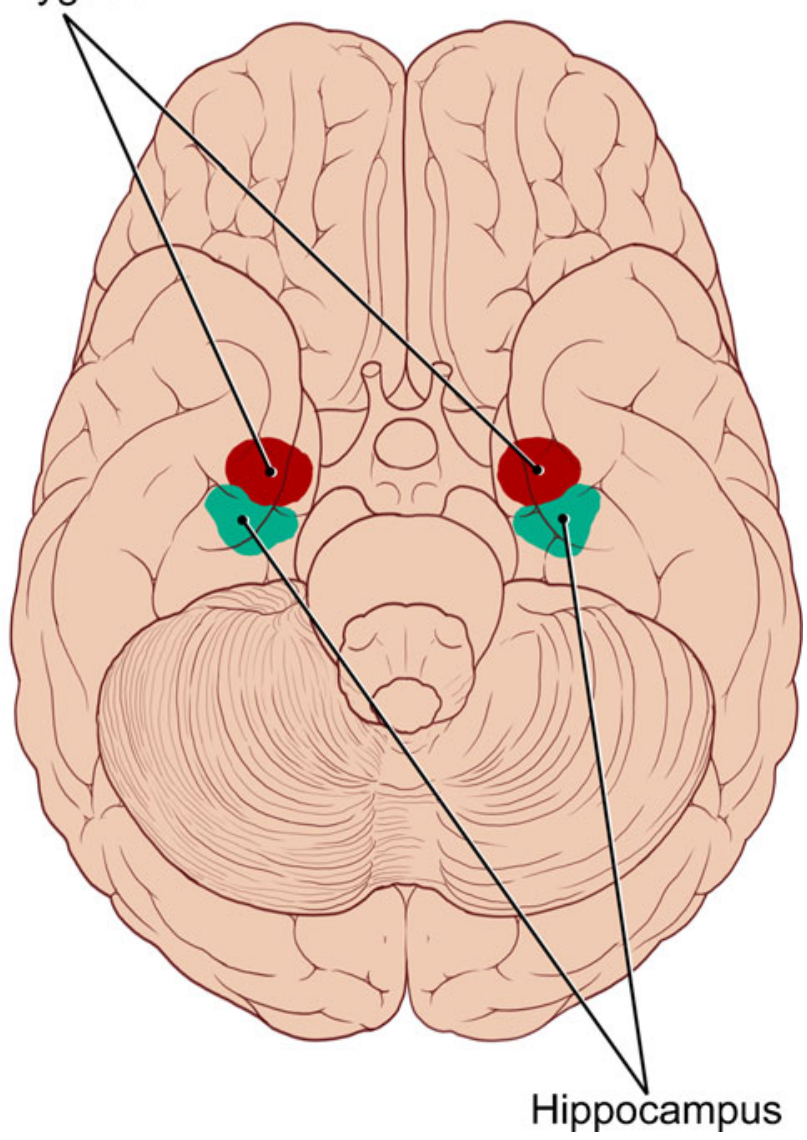

Fig. 1 a Sagittal view of neuroanatomic regions affected by music (and implicated in the pathophysiology of pain, anxiety, and/or depression). b Inferior view of neuroanatomic regions affected by music (and implicated in the pathophysiology of pain, anxiety, and/or depression) 
outcome to cancer patients in palliative care settings, future studies investigating the effect of music-based interventions on pain, anxiety, or mood disturbance in this patient population should incorporate QOL measurements into their outcome assessment.

\section{Relevant advances in neurobiology}

Previous speculations regarding the potential mechanisms of music-based interventions may have drastically oversimplified an extremely complex set of possible neurobiological processes [78]. Many investigators have proposed that music may compete with noxious stimuli and thereby close neurological gates of pain signal transmission, or that it may distract patients from threats that cause them to feel anxious, and/or that it may promote a sense of well-being in patients with an otherwise depressed mood. While these may all be valid theories, advances in neuroscience, and functional neuroimaging studies in particular, are providing dramatic new insights into the findings from clinical trials involving music-based interventions (Table 5).

Multiple studies have explored changes in activity within the brains of healthy, asymptomatic adults upon exposure to music. Broadly speaking, functional imaging data have shown that music modulates the activity of multiple limbic and paralimbic brain structures, but especially the ventral striatum (including the nucleus accumbens), the dorsomedial midbrain (including the ventral tegmental area and periaqueductal gray), the amygdala, and the hippocampus (Fig. 1a, b). This particular neuroanatomic distribution is striking for at least two reasons. The first is that functional abnormalities in these same structures are implicated in the pathophysiology of pain [79-81], anxiety [82-84], and depression [85-87]. The second is that these same structures are known to be densely populated by receptors of ligands associated with pain, anxiety, and depression - namely, endogenous opioids [88, 89], GABA [90, 91], and dopamine [92, 93].

Listening to music has long been known to evoke strong emotional responses which can sometimes be accompanied by physical manifestations, e.g., piloerection, more commonly known as "goosebumps" or "chills" [94, 95]. The suppression of this response with the mu-opioid receptor agonist nalaxolone provided early evidence that endogenous opioid activity might underlie pleasurable responses to music [96]. Positron emission tomography experiments subsequently showed that piloerection in response to music may be associated with increased regional cerebral blood flow to the ventral striatum and the dorsomedial midbrain but decreased regional cerebral blood flow (rCBF) to the hippocampus and amygdala [97]. Even in the absence of piloerective responses, fMRI evidence suggested that consonant musical excerpts may increase activity in the ventral striatum and the anterior insula $[98,99]$, while dissonant excerpts may increase activity in the amygdala and hippocampus [99]. Data collected from $\left[{ }^{11} \mathrm{C}\right]$ raclopride $\mathrm{PET}$ demonstrated that intensely pleasurable responses to music may be associated with dopamine release in the striatal system [100]. This dopaminergic activity in the NAc following exposure to music (and other pleasurable stimuli, e.g., sex, food, and drugs of abuse) may itself be modulated by endogenous opioids [101]. Furthermore, evidence from animal models suggests that opioid efferent projections from the NAc may directly mediate reward-related behavior [102]. Within the dorsomedial midbrain (which was found to receive increased $\mathrm{rCBF}$ during highly pleasurable musical experiences as shown in [97]), the substructure known as the periaqueductal gray has been shown to be densely populated with endogenous opioid receptors and may be involved in both opioid-mediated reward [103] and analgesia [79, 104]. Preliminary research suggests that the action of endogenous opioids in the PAG may be influenced by the hormone oxytocin [105]; the blood concentrations of which was found to be increased (along with subjective relaxation) in perioperative patients exposed to soothing music [106]. Although multiple functional imaging studies have shown music to modulate the activity of the amygdala [97, 107], and multiple functional imaging studies have demonstrated an association between anxiety and enhanced amygdalar activity [82, 83, 108, 109], no radioligand binding experiments have specifically investigated the effect of music on gamma amino-butyric acid activity in the brain. With regard to mood disturbance, it is worth noting that music has been shown to modulate the activity of the subcallosal cingulate region [107, 110], an area which has been shown to have

Fig. 2 General conceptual model for the potentially therapeutic impact(s) of music-based interventions in cancer patients

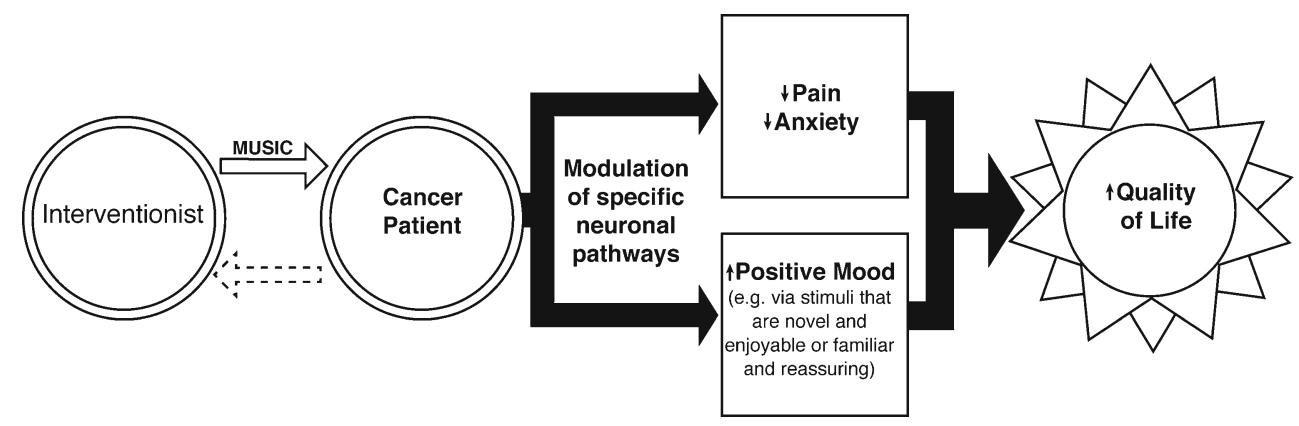


decreased $\mathrm{rCBF}$ in patients with depression [111]. Furthermore, deep brain stimulation of the subcallosal cingulate region has been shown to be an effective treatment for severe depression [86]. Finally, platelet concentrations of serotonin, which may correlate with neuronal concentrations of seroto$\operatorname{nin}[112,113]$, were found to be increased in humans exposed to euphonic music, but decreased in humans exposed to cacophonic music [114].

Overall, these advances in neurobiology suggest that music may affect specific neuronal pathways that are implicated in the pathophysiology of pain, anxiety, and depression. Thus, future neurobiological studies may provide objective insight into the mechanisms by which music may affect these subjective symptoms that commonly afflict patients with cancer.

\section{Conclusions}

In 2002, the WHO approved the following definition of palliative care: "An approach that improves the quality of life of patients and their families facing the problems associated with life-threatening illness, through the prevention and relief of suffering by means of early identification and impeccable assessment and treatment of pain and other problems, physical, psychosocial and spiritual" [115]. In the future, music-based interventions may prove to become valuable tools in the "relief of suffering" of cancer patients. Specifically, music may help alleviate pain, anxiety, and mood disturbance, all of which commonly occur in cancer, and all of which may be associated with impaired QOL. The potential of music to reduce the need for analgesics and/or anxiolytics, even if only by a small amount, may still have major clinical implications, especially given the frequency with which advanced age and hepato-renal dysfunction coexist in the palliative cancer care population (and hence their predisposition to pharmacologic toxicity). Furthermore, when the only pharmacologic agents available for mood disturbance take weeks to months to take effect, interventions that provide more immediate benefits, even if modest, may warrant further investigation.

It is not difficult to imagine how, for cancer patients unfamiliar with the standard inpatient healthcare environment, the hospital setting could be associated with unexpected pain (e.g., from repeated injections, blood draws, and other invasive procedures), anxiety (e.g., from loud equipment alarms and time-constrained conversations regarding prognosis often clouded by medical jargon), and even depression (e.g., related to the existential issues of having a life-threatening illness, limited social interaction, frequently interrupted sleep, etc.). The capacity of music to restore a sense of familiarity, and the therapeutic value of such a reassuring stimulus (regardless of where a patient may be in his or her disease trajectory), may be underestimated. Such reassuring familiarity could be provided in the form of a playlist of favorite songs on a portable mp3 player with headphones or even through melodic arrangement by a live music therapist that actually incorporates tones from the surrounding environment [116]. It should not necessarily be assumed that the benefits of music are limited to the relief of symptoms; that is to say, that music merely counteracts the negative consequences of disease (Fig. 2). The need for beauty (and for some, spiritual solace) may be particularly great toward the end of life for many patients. In this respect, music may exceed where standard pharmacologic means fall short. Many qualitative studies support both the potential symptomalleviating and wellness-promoting effects of music $[3,10$, 117-125]. However, quantitative data in these areas still remain limited.

In the absence of more RCTs with larger sample sizes, meta-analyses $[13,20,126]$ can provide useful quantitative assessments of impact. However, controlling for variation in study design, study population, specific intervention(s), and outcome assessment methods, presents enormous challenges. For example, different music therapists can introduce variability in outcomes, even when the same specific interventions are used [127]. The data presented in the individual trials and the meta-analyses discussed in this review should therefore be considered preliminary and interpreted with caution. The statistical quality of the data in question remains diminished by high risk of bias, which almost invariably arises from the inherent difficulties associated with conventional blinding in music-based intervention studies. Furthermore, without reliable biomarkers for pain, anxiety, and depression, defining the "gold standard" in quantitative assessment of these outcomes remains formidable. Fortunately, the cost of music-based interventions remains relatively low [128], and breakthroughs in the field of neurobiology continue to advance our understanding of the anatomical and biochemical basis of how music works in the brain, and why symptoms such as pain, anxiety, and mood disturbance might be influenced.

Further investigation is warranted to determine (1) if certain subpopulations of cancer patients are more likely to respond to music-based interventions than others, (2) what interventions are most effective for such responsive patients, and (3) what measurement parameters best gauge their effectiveness. Greater collaboration between the fields of music therapy and music neuroscience may accelerate the pursuit of these objectives. Finally, given the emerging evidence that earlier involvement of palliative care may improve outcomes in certain cancer patients [129], and that psychological stress may be linked to up-regulation of inflammatory processes that promote tumor growth and angiogenesis [130-133], it follows that research into the potential of music to specifically promote relaxation and reduce stress [134], perhaps earlier in cancer's trajectory, may also be warranted. 
Acknowledgments Thanks to David Aten of MDACC Medical Graphics \& Photography for illustrating all figures and to Mei Dong and Biquan Luo for the help with translation.

Conflict of Interest I have no financial relationships to disclose. I have full control over the content of this article. I submit the entirety of this manuscript for review by Supportive Care in Cancer.

Open Access This article is distributed under the terms of the Creative Commons Attribution Noncommercial License which permits any noncommercial use, distribution, and reproduction in any medium, provided the original author(s) and the source are credited.

\section{References}

1. Smith EM, Gomm SA (2003) Assessing the independent contribution to quality of life from anxiety and depression in patients with advanced cancer. Palliat Med 17(6):509-509

2. Ferrell BR (1995) The impact of pain on quality of life. A decade of research. Nurs Clin N Am 30(4):609-624

3. O'Callaghan C (2009) Objectivist and constructivist music therapy research in oncology and palliative care. Music Med 1(1):41-60

4. Olofsson A, Fossum B (2009) Perspectives on music therapy in adult cancer care: a hermeneutic study. Oncol Nurs Forum 36(4):1-10

5. Gallagher L, Lagman R, Walsh D, Davis M, LeGrand S (2006) The clinical effects of music therapy in palliative medicine. Support Care Cancer 14(8):859-866. doi:10.1007/s00520-005-0013-6

6. Stanczyk MM (2011) Music therapy in supportive cancer care. Rep Pract Oncol Radiother 16(5):170-172

7. Trondalen G, Bonde LO (2012) Music therapy: models and interventions. In: MacDonald R, Kreutz G, Mitchell L (eds) Music, health, and wellbeing. Oxford University Press, New York, pp 40-64

8. Dileo C (1999) Music therapy and medicine: theoretical and clinical applications. American Music Therapy Association, Silver Spring

9. Bruscia K (1998) Defining music therapy, 2nd edn. Barcelona, Gilsum

10. Munro S, Mount B (1978) Music therapy in palliative care. Can Med Assoc J 119(9):1029-1034

11. van den Beuken-van EM, de Rijke J, Kessels A, Schouten H, van Kleef M, Patijn J (2007) Prevalence of pain in patients with cancer: a systematic review of the past 40 years. Ann Oncol 18(9):1437-1449

12. Higginson IJ, Murtagh F (2010) Cancer pain epidemiology. In: Bruera E, Portenoy RK (eds) Cancer pain: assessment and management, vol 2. Cambridge University Press, New York, pp 37-52

13. Bradt J, Dileo C, Grocke D, Magill L (2011) Music interventions for improving psychological and physical outcomes in cancer patients. Cochrane Database of Systematic Reviews (8). doi:10.1002/14651858

14. Binns-Turner P (2008) Perioperative music and its effects on anxiety, hemodynamics, and pain in women undergoing mastectomy. University of Alabama, Birmingham

15. Danhauer SC, Vishnevsky BA, Campbell CR, McCory TP, Tooze JA, Kanipe KN, Arrington SA, Holland EK, Lynch MB, Hurd DD, Cruz J (2010) Music for patients with hematological malignancies undergoing bone marrow biopsy: a randomized controlled study of anxiety, perceived pain, and patient satisfaction. J Soc Integr Oncol 8(4):140-147

16. Huang S (2006) The effects of music on cancer pain. Case Western Reserve University, Cleveland
17. Nguyen TN, Nilsson S, Hellstrom A, Bengtson A (2010) Music therapy to reduce pain and anxiety in children with cancer undergoing lumbar puncture: a randomized clinical trial. J Pediatr Oncol Nurs 27:146-155

18. Yonghui W, Zongfu M, Yanru Q (2009) Influence of music therapy on anxiety, depression and pain of cancer patients. Chin Nurs Res 13:1172-1175

19. Cepeda MS, Carr DB, Lau J, Alvarez H (2006) Music for pain relief. Cochrane Database of Systematic Reviews 2:CD004843

20. Rudin D, Kiss A, Wetz RV, Sottile VM (2007) Music in the endoscopy suite: a meta-analysis of randomized controlled studies. Endoscopy 39:507-510

21. Smolen D, Topp R, Singer L (2002) The effect of self-selected music during colonoscopy on anxiety, heart rate, and blood pressure. Appl Nurs Res 15(3):126-136. doi:10.1053/apnr.2002.34140

22. Lee DWH, Chan K-W, Poon C-M, Ko C-W, Chan K-H, Sin K-S, Sze T-S, Chan ACW (2002) Relaxation music decreases the dose of patient-controlled sedation during colonoscopy: a prospective randomized controlled trial. Gastrointest Endosc 55(1):33-36. doi:10.1067/mge.2002.120387

23. Schiemann U, Gross M, Reuter R (2002) Improved procedure of colonoscopy under accompanying music therapy. Eur J Med Res 7:131-134

24. Stark D, Kiely M, Smith A, Velikova G, House A, Selby P (2002) Anxiety disorders in cancer patients: their nature, associations, and relation to quality of life. J Clin Oncol 20(14):3137-3148

25. Zimmerman L, Story KT, Gaston-Johansson F, Rowles JR (1996) Psychological variables and cancer pain. Cancer Nurs 19:44-53

26. Mystakidou K, Tsilika E, Parpa E, Katsouda E, Galanos A, Vlahos L (2006) Psychological distress of patients with advanced cancer: influence and contribution of pain severity and pain interference. Cancer Nurs 29:400-405

27. Lin C-C, Lai Y-L, Ward SE (2003) Effect of cancer pain on performance status, mood states, and level of hope among Taiwanese cancer patients. J Pain Symptom Manag 25(1):29-37

28. Dahl A, Haaland C, Mykletun A, Bremnes R, Dahl O, Klepp O, Wist E, Fosså S (2005) Study of anxiety disorder and depression in long-term survivors of testicular cancer. J Clin Oncol 23(10):2389-2395

29. Brintzenhofe-Szoc KM, Levin TT, Li Y, Kissane DW, Zabora JR (2009) Mixed anxiety/depression symptoms in a large cancer cohort: prevalence by cancer type. Psychosomatics 50(4):383-391

30. Kolva E, Rosenfeld B, Pessin H, Breitbart W, Brescia R (2011) Anxiety in terminally ill cancer patients. J Pain Symptom Manag 42(5):691-701

31. Teunissen SCCM, de Graeff A, Voest EE, de Haes JCJM (2007) Are anxiety and depressed mood related to physical symptom burden? A study in hospitalized advanced cancer patients. Palliat Med 21(4):341-346. doi:10.1177/0269216307079067

32. Spencer R, Nilsson M, Wright A, Pirl W, Prigerson H (2010) Anxiety disorders in advanced cancer patients. Cancer 116(7):1810-1819

33. Wilson KGC HM, Graham SM, Allard P, Chary S, Gagnon P, Macmillan K, De Luca M, O'Shea F, Kuhl D, Fainsinger RL, Clinch JJ (2007) Depression and anxiety disorders in palliative cancer care. J Pain Symptom Manag 33(2):118-129

34. Bufalini A (2009) Role of interactive music in oncological pediatric patients undergoing painful procedures. Minerva Pediatr 61(4):379-389

35. Bulfone T, Quattrin R, Zanotti R, Regattin L, Brusaferro S (2009) Effectiveness of music therapy for anxiety reduction in women with breast cancer in chemotherapy treatment. Holist Nurs Pract 23(4):238-242

36. Harper EI (2001) Reducing treatment-related anxiety in cancer patients: comparison of psychological interventions. Southern Methodist University, Dallas 
37. Smith M, Casey L, Johnson D, Gwede C, Riggin OZ (2001) Music as a therapeutic intervention for anxiety in patients receiving radiation therapy. Oncol Nurs Forum 28(5):855-862

38. Cooke M, Chaboyer W, Schluter P, Hiratos M (2005) The effect of music on preoperative anxiety in day surgery. J Adv Nurs $52(1): 47-55$

39. Nilsson U, Rawal N, Unosson M (2003) A comparison of intraoperative or postoperative exposure to music - a controlled trial of the effects on postoperative pain. Anaesthesia 58(7):699-703

40. Nilsson U, Unosson M, Rawal N (2005) Stress reduction and analgesia in patients exposed to calming music postoperatively: a randomized controlled trial. Eur J Anaesthesiol 22(2):96-102

41. Voss J, Good M, Yates B, Baun M, Thompson A, Hertzog M (2004) Sedative music reduces anxiety and pain during chair rest after open-heart surgery. Pain 112(1-2):197-203

42. Horne-Thompson A, Grocke D (2008) The effect of music therapy on anxiety in patients who are terminally ill. J Palliat Med 11(4):582-590

43. Bringman H, Giesecke K, ThÖRne A, Bringman S (2009) Relaxing music as pre-medication before surgery: a randomised controlled trial. Acta Anaesthesiol Scand 53(6):759-764. doi:10.1111/j.13996576.2009.01969.x

44. McHugh P, Lewis S, Ford S, Newlands E, Rustin G, Coombes C, Smith D, O'Reilly S, Fallowfield L (1995) The efficacy of audiotapes in promoting psychological well-being in cancer patients: a randomised, controlled trial. Br J Cancer 71(2):388-392

45. Noyes RJ, Holt C, Massie M (1998) Anxiety disorders. In: Holland J (ed) Psycho-oncology. Oxford University Press, New York, pp 548-563

46. Hinton J (1972) Psychiatric consultation in fatal illness. Proc R Soc Med 65(11):1035

47. Bukberg JB, Holland JC (1980) A prevalence study of depression in a cancer hospital population. Proc Am Assoc Cancer Res $21: 382$

48. Derogatis L, Morrow G, Fetting J, Penman D, Piasetsky S, Schmale A, Henrichs M, Carnicke C (1983) The prevalence of psychiatric disorders among cancer patients. JAMA: J Am Med Assoc 249(6):751-757

49. Chochinov H, Wilson K, Enns M (1994) Prevalence of depression in the terminally ill: effects of diagnostic criteria and symptom threshold judgements. Am J Psychiatry 151:537-540

50. Craig TJ, Abeloff MD (1974) Psychiatric symptomatology among hospitalized cancer patients. Am J Psychiatr 131(12):1323-1327

51. Achute K, Vauhkonen ML (1970) Cancer and psyche. Kunnallispaino, Helsinki

52. Peck A (1972) Emotional reactions to having cancer. Am J Roentgenol 114(3):591-599

53. Mitchell AJ, Chan M, Bhatti H, Halton M, Grassi L, Johansen C, Meader N (2011) Prevalence of depression, anxiety, and adjustment disorder in oncological, haematological, and palliative-care settings: a meta-analysis of 94 interview-based studies. Lancet Oncol 12(2):160-174

54. Guangrong C, Yi Q, Peiwen L (2001) Music therapy in treatment of cancer patients. Chin Ment Heal J 15(3):179-181

55. Cassileth BR, Vickers AJ, Magill LA (2003) Music therapy for mood disturbance during hospitalization for autologous stem cell transplantation. Cancer 98(12):2723-2729

56. Clark M, Isaacks-Downton G, Wells N, Redlin-Frazier S, Eck C, Hepworth J, Chakravarthy B (2006) Use of preferred music to reduce emotional distress and symptom activity during radiation therapy. J Music Ther 43(3):247-265

57. Hanser SB (2006) Effects of a music therapy intervention on quality of life and distress in women with metastatic breast cancer. J Soc Integr Oncol 4(3):116-124

58. Beck S (1989) The effect of therapeutic use of music on cancer related pain. PhD thesis, University of Utah, Salt Lake City
59. Duocastella AC (1999) Effect of music on children with cancer. Revista de Enfermeria 22(4):293-298

60. de Haes JC, Van Knippenberg FC (1985) The quality of life of cancer patients: a review of the literature. Soc Sci Med 20(8):809-817

61. Brucker PS, Yost K, Cashy J, Webster K, Cella D (2005) General Population and cancer patient norms for the Functional Assessment of Cancer Therapy-General (FACT-G). Eval Health Prof 28(2):192-211. doi:10.1177/0163278705275341

62. Hammerlid E, Taft C (2001) Health-related quality of life in longterm head and neck cancer survivors: a comparison with general population norms. Br J Cancer 84(2):149-156

63. Donovan KA, Thompson LM, Jacobsen PB (2012) Pain, depression, and anxiety in cancer. In: Moore RJ (ed) Handbook of pain and palliative care: biobehavioral approaches for the life course. Springer, Heidelberg, pp 615-637

64. Padilla GV, Ferrell B, Grant MM, Rhiner M (1990) Defining the content domain of quality of life for cancer patients with pain. Cancer Nurs 13:108-115

65. Wang XS, Cleeland CS, Mendoza TR, Engstrom MC, Liu S, Xu G, Hao X, Wang Y, Ren XS (1999) The effects of pain severity on health-related quality of life. Cancer 86(9):1848-1855

66. Berthold DR, Pond GR, Roessner M, de Wit R, Eisenberger M, Tannock I (2008) Treatment of hormone-refractory prostate cancer with docetaxel or mitoxantrone: relationships between prostate-specific antigen, pain, and quality of life response and survival in the TAX-327 Study. Clin Cancer Res 14(9):27632767. doi:10.1158/1078-0432.ccr-07-0944

67. Breivik H, Cherny N, Collett B, de Conno F, Filbet M, Foubert A, Cohen R, Dow L (2009) Cancer-related pain: a pan-European survey of prevalence, treatment, and patient attitudes. Ann Oncol 20(8):1420-1433

68. So W, Marsh G, Ling W, Leung F, Lo J, Yeung M, Li G (2009) The symptom cluster of fatigue, pain, anxiety, and depression and the effect on the quality of life of women receiving treatment for breast cancer: a multicenter study. Oncol Nurs Forum 36(4):E205-E214

69. Skarstein J, Aass N, Fosså S, Skovlund E, Dahl A (2000) Anxiety and depression in cancer patients: relation between the Hospital Anxiety and Depression Scale and the European Organization for Research and Treatment of Cancer Core Quality of Life Questionnaire. J Psychosom Res 49(1):27-34

70. Saevarsdottir T, Fridriksdottir N, Gunnarsdottir S (2010) Quality of life and symptoms of anxiety and depression of patients receiving cancer chemotherapy: longitudinal study. Cancer Nurs 33(1):E1-E10

71. Pereira MG, Figueiredo AP, Fincham FD (2012) Anxiety, depression, traumatic stress and quality of life in colorectal cancer after different treatments: a study with Portuguese patients and their partners. Eur J Oncol Nurs 16(3):227-232

72. Payne $S$ (1992) A study of quality of life in cancer patients receiving palliative chemotherapy. Soc Sci Med 35(12):1505-1509

73. Grassi L, Indelli M, Marzola M, Maestri A, Santini A, Piva E, Boccalon M (1996) Depressive symptoms and quality of life in home-care-assisted cancer patients. J Pain Symptom Manag 12(5):300-307

74. Brown L, Kroenke K, Theobald D, Wu J, Tu W (2010) The association of depression and anxiety with health-related quality of life in cancer patients with depression and/or pain. PsychoOncology 19(7):734-741

75. Burns D (2001) The effect of the bonny method of guided imagery and music on the mood and life quality of cancer patients. J Music Ther 38(1):51-65

76. Hilliard R (2003) The effects of music therapy on the quality and length of life of people diagnosed with terminal cancer. J Music Ther 40(2):113-137 
77. Zhong X, Gang H (2001) Effect of music therapy and relaxation inner image on quality of life in cancer patients receiving chemotherapy. Chinese Mental Health J 15(3):176-178

78. Koelsch S (2009) A neuroscientific perspective on music therapy. Ann N Y Acad Sci 1169(1):374-384

79. Becerra L, Breiter HC, Wise R, Gonzalez RG, Borsook D (2001) Reward circuitry activation by noxious thermal stimuli. Neuron 32(5):927

80. Chen A (2001) New perspectives in EEG/MEG brain mapping and PET/fMRI neuroimaging of human pain. Int J Psychophysiol 42(2):147-159

81. Millan MJ (2002) Descending control of pain. Prog Neurobiol 66(6):355-474. doi:10.1016/s0301-0082(02)00009-6

82. Engel K, Bandelow B, Gruber O, Wedekind D (2009) Neuroimaging in anxiety disorders. J Neural transm 116(6):703-716

83. Stein MB, Simmons AN, Feinstein JS, Paulus MP (2007) Increased amygdala and insula activation during emotion processing in anxiety-prone subjects. Am J Psychiatry 164:318-327

84. Martin EI, Ressler KJ, Binder E, Nemeroff CB (2009) The neurobiology of anxiety disorders: brain imaging, genetics, and psychoneuroendocrinology. Psychiatr Clin N Am 32:549-575

85. Nestler EJ, Carlezon WA (2006) The mesolimbic dopamine reward circuit in depression. Biol Psychiatry 59(12):1151-1159

86. Mayberg HS (1997) Limbic-cortical dysregulation: a proposed model of depression. J Neuropsychiatry Clin Neurosci 9(3):471-481

87. Drevets WC, Price JL, Bardgett ME, Reich T, Todd RD, Raichle ME (2002) Glucose metabolism in the amygdala in depression: relationship to diagnostic subtype and plasma cortisol levels. Pharmacol Biochem Behav 71(3):431-447

88. Koneru A, Satyanarayana S, Rizwan S (2009) Endogenous opioids: their physiological role and receptors. Global J Pharmacol 3(3):149-153

89. Akil H, Watson SJ, Young E, Lewis ME, Khachaturian H, Walker JM (1984) Endogenous opioids: biology and function. Annu Rev Neurosci 7(1):223-255. doi:10.1146/ annurev.ne.07.030184.001255

90. McDonald AJ, Mascagni F, Muller JF (2004) Immunocytochemical localization of GABABR1 receptor subunits in the basolateral amygdala. Brain Res 1018(2):147-158

91. Gray JA, McNaughton N (2003) The neuropsychology of anxiety: an enquiry into the functions of the septo-hippocampal system. Oxford Psychology Series, vol 33, 2nd edn. Oxford University Press, New York

92. Levey AI, Hersch SM, Rye DB, Sunahara RK, Niznik HB, Kitt CA, Price DL, Maggio R, Brann MR, Ciliax BJ (1993) Localization of D1 and D2 dopamine receptors in brain with subtype-specific antibodies. Proc Natl Acad Sci U S A 90(19):8861-8865

93. Dailly E, Chenu F, Renard CE, Bourin M (2004) Dopamine, depression and antidepressants. Fundam Clin Pharmacol 18(6):601-607. doi:10.1111/j.1472-8206.2004.00287.x

94. Panksepp J (1995) The emotional sources of "chills" induced by music. Music Percept 13(2):171-207

95. Khalfa S, Peretz I, Blondin J, Manon R (2002) Event-related skin conductance responses to musical emotions in humans. Neurosci Lett 328(2):145-149

96. Goldstein A (1980) Thrills in response to music and other stimuli. Physiol Psychol 8(1):126-129

97. Blood AJ, Zatorre RJ (2001) Intensely pleasurable responses to music correlate with activity in brain regions implicated in reward and emotion. Proc Natl Acad Sci 98(20):11818-11823

98. Menon V, Levitin DJ (2005) The rewards of music listening: response and physiological connectivity of the mesolimbic system. NeuroImage 28(1):175-184
99. Koelsch S, Fritz T, Müller K, Friederici AD (2005) Investigating emotion with music: an fMRI study. Human Brain Mapp 27(3):239-250

100. Salimpoor VN, Benovoy M, Larcher K, Dagher A, Zatorre RJ (2011) Anatomically distinct dopamine release during anticipation and experience of peak emotion to music. Nat Neurosci 14(2):257-262

101. Bardo M (1998) Neuropharmacological mechanisms of drug reward: beyond dopamine in the nucleus accumbens. Crit Rev Neurobiol 12:37-67

102. Gardner EL, Vorel SR (1998) Cannabinoid transmission and reward-related events. Neurobiol Dis 5(6):502-533

103. Olmstead MC, Franklin KBJ (1997) The development of a conditioned place preference to morphine: effects of micro-injections into various CNS sites. Behav Neurosci 111:1324-1334

104. Pavlovic ZW, Bodnar RJ (1998) Opioid supraspinal analgesic synergy between the amygdala and periaqueductal gray in rats. Brain Res 779(1-2):158-169

105. Yang J, Liang J-Y, Li P, Pan Y-J, Qiu P-Y, Zhang J, Hao F, Wang D-X (2011) Oxytocin in the periaqueductal gray participates in pain modulation in the rat by influencing endogenous opiate peptides. Peptides 32(6):1255-1261. doi:10.1016/ j.peptides.2011.03.007

106. Nilsson U (2009) Soothing music can increase oxytocin levels during bed rest after open-heart surgery: a randomised control trial. J Clin Nurs 18(15):2153-2161. doi:10.1111/j.13652702.2008.02718.x

107. Pereira CS, Teixeira J, Figueiredo P, Xavier J, Brattico E (2011) Music and emotions in the brain: familiarity matters. PLoS One 6(11):e27241

108. Phan KL, Wager T, Taylor SF, Liberzon I (2002) Functional neuroanatomy of emotion: a meta-analysis of emotion activation studies in PET and fMRI. NeuroImage 16(2):331

109. Somerville LH, Kim H, Johnstone T, Alexander AL, Whalen PJ (2004) Human amygdala responses during presentation of happy and neutral faces: correlations with state anxiety. Biol Psychiatry 55(9):897-903

110. Blood AJ, Zatorre RJ, Bermudez P, Evans AC (1999) Emotional responses to pleasant and unpleasant music correlate with activity in paralimbic brain regions. Nat Neurosci 2(4):382-382

111. Drevets WC, Price JL, Simpson JR, Todd RD, Reich T, Vannier M, Raichle ME (1997) Subgenual prefrontal cortex abnormalities in mood disorders. Nature 386(6627):824-827

112. Stahl SM (1977) The human platelet: a diagnostic research tool for the study of biogenic amines in psychiatric and neurologic disorders. Arch Gen Psychiatry 34:509-516

113. Pletscher A (1978) Platelets as models for monoaminergic neurons. In: Youdim MBH (ed) Essays in neurochemistry and neuropharmacology, vol 3. Wiley, London, pp 49-101

114. Evers S, Suhr B (2000) Changes of the neurotransmitter serotonin but not of hormones during short time music perception. Eur Arch Psychiatry Clin Neurosci 250(3):144-147. doi:10.1007/ s004060070031

115. Organization WH (2013) http://www.who.int/cancer/palliative/defini tion/en/. Accessed 30 March 2012

116. Rosetti A (2011) Treating stress, speech disorders with music. NPR Science Friday (December 16)

117. Magill L (2001) The use of music therapy to address the suffering in advanced cancer pain. J Palliat Care 17(3):167

118. Daykin N, Bunt L, McClean S (2006) Music and healing in cancer care: a survey of supportive care providers. Arts Psychother 33(5):402-413

119. Magill-Levreault L (1993) Music therapy in pain and symptom management. J Palliat Care 9(4):42-48

120. O'Kelly J, Koffman J (2007) Multidisciplinary perspectives of music therapy in adult palliative care. Palliat Med 21(3):235-241 
121. Mandel SE (1993) The role of the music therapist on the hospice/ palliative care team. J Palliat Care 9(4):37-39

122. Munro S (1984) Music therapy in palliative/hospice care. Magnamusic-Baton, New York

123. Hilliard RE (2001) The use of music therapy in meeting the multidimensional needs of hospice patients and families. J Palliat Care 17(3):161-166

124. Dileo C, Loewy JV (2005) Music therapy at the end of life. Jeffrey, Cherry Hill

125. Von Hodenberg F (1995) Music therapy with patients undergoing radiation and chemotherapy. Lonely waters. Sobell, Oxford, pp 61-67

126. Bradt J, Dileo C (2010) Music therapy for end-of-life care. Cochrane Database of Systematic Reviews (1). doi:10.1002/ 14651858.CD007169.pub2

127. Kain ZN, Caldwell-Andrews AA, Krivutza DM, Weinberg ME, Gaal D, Wang S-M, Mayes LC (2004) Interactive music therapy as a treatment for preoperative anxiety in children: a randomized controlled trial. Anesth Analg 98(5):1260-1266. doi:10.1213/ 01.ane.0000111205.82346.c1

128. Romo R, Gifford L (2007) A cost-benefit analysis of music therapy in a home hospice. Nurs Econ 25(6):353-358

129. Temel J, Greer J, Muzikansky A, Gallagher E, Admane SJ VA, Dahlin C, Blinderman C, Jacobsen J, Pirl W, Billings J, Lynch T
(2010) Early palliative care for patients with metastatic nonsmall-cell lung cancer. N Engl J Med 363(8):733-742

130. Thaker P, Han L, Kamat A, Arevalo J, Takahashi R, Lu C, Jennings N, Armaiz-Pena G, Bankson J, Ravoori M, Merritt W, Lin Y, Mangala L, Kim T, Coleman R, Landen C, Li Y, Felix E, Sanguino A, Newman R, Lloyd M, Gershenson D, Kundra V, Lopez-Berestein G, Lutgendorf S, Cole S, Sood A (2006) Chronic stress promotes tumor growth and angiogenesis in a mouse model of ovarian carcinoma. Nat Med 12(8):939-944

131. Cohen L, Cole SW, Sood AK, Prinsloo S, Kirschbaum C, Arevalo JMG, Jennings NB, Scott S, Vence L, Wei Q, Kentor D, Radvanyi L, Tannir N, Jonasch E, Tamboli P, Pisters L (2012) Depressive symptoms and cortisol rhythmicity predict survival in patients with renal cell carcinoma: role of inflammatory signaling. PLoS One 7(8):e42324. doi:10.1371/ journal.pone.0042324

132. Moreno-Smith M, Lutgendorf SK, Sood AK (2010) Impact of stress on cancer metastasis. Futur Oncol 6(12):1863-1881. doi: $10.2217 /$ fon. 10.142

133. Armaiz-Pena GN, Lutgendorf SK, Cole SW, Sood AK (2009) Neuroendocrine modulation of cancer progression. Brain, Behav Immun 23(1):10-15. doi:10.1016/j.bbi.2008.06.007

134. Yehuda N (2011) Music and stress. J Adult Develop 18(2):85-94 